\title{
Factors governing the fire response of prestressed reactive powder concrete beams
}

\begin{abstract}
This paper presents the details of fire test on eight prestressed reactive powder concrete (RPC) beams cured with $150^{\circ} \mathrm{C}$ hot-air condition. The test specimens were varied in load ratios/degree, cover thicknesses of tendons, bonded and unbonded tendons, partial prestressing ratios. The thermal fields, deflections behaviour, effective prestress, fire endurance, failure modes, and crack patterns of the beams were observed and recorded during the tests. The post-fire tests observation reveals that no obvious thermal-induced spalling occurred on the prestressed RPC beams prepared in hot-air curing. The fire tests results indicated that the failure of prestressed RPC beams was driven by direct fire exposure and fracture of tendons and longitudinal rebars after generation of wide cracks in the beams. In extreme fire, prestressed RPC beams that are under-reinforced at ambient temperature may fail as the low-reinforced beams. The load ratios and cover thicknesses of tendons are the key factors affecting the fire resistance of the prestressed RPC beams. With the decrease of the load ratios and increase of cover thicknesses of tendons, the fire resistance is dramatically improved. Bonded prestressed RPC beams showed superior performance to equivalent unbonded prestressed RPC beams in fire. The whole scale transferring effect of prestress loss in unbonded beams should be considered for fire resistance performance design based on structural systems.
\end{abstract}

\section{Introduction}

Ultra-high performance reactive powder concrete (RPC) is a green novel construction material. RPC basically consists of cement, reactive powders admixture (silica fume, fly ash, and slag), quartz, super plasticizer and fibres[1]. Under standard ambience curing, the compressive strength of RPC can be reached $100 \sim 150 \mathrm{MPa}$. While, under $70-90^{\circ} \mathrm{C}$ steam curing, compressive and tensile strength can be improved to 150-230MPa and 8-20MPa respectively. Due to ultra-high strength, excellent durability and outstanding seismic energy dissipation performance [2], and also with the implementation of the design standards for RPC in France[3], Germany[4], China[5] and Japan[6], the development and applications of RPC is being widely spread in bridges, offshore structures, civil buildings and infrastructure engineering. Especially in high-rise buildings, large-span structures, and prefabricated buildings, RPC possesses unique advantages. For calculating the flexural capacity of RPC beams, the tensile strength of RPC can be added up since the 
contribution from RPC in tensile region accounts for $15-40 \%$ of the whole flexural capacity [7], [8]. In condition of satisfying flexural capacity, the volume of RPC beams is only about one third of equivalent normal strength concrete (NSC) beams. On this account, the replacement of RPC to NSC could reduce approximate $50 \%$ of cement, aggregate and $\mathrm{CO}_{2}$ emission. However, when endure heavy loads and large spans in actual structure, small cross-section RPC beams have high risks on the deflection limit and crack. For this reason, high-strength prestressing tendons are introduced in generally to form prestressed RPC beams. Prestressed RPC beams with appropriate prestress forces can maximize material mechanical superiorities of RPC and tendons as well as endow with an excellent resistance of deflection and crack.

Fire resistance is important in this new RPC structural member, because it is not only a major fire safety requirement in structural design, but also a criterion to judge the failure of structural members under fire conditions. RPC has a high probability of spalling in fire due to its dense microstructure and low permeability[9]. The previous test studies have investigated RPC spalling concentrated on small-sized specimens without imposed loads at the heating rate ranged $3-20^{\circ} \mathrm{C} / \mathrm{min}[10-12]$. Mainly based on experimental test results, prediction and controlling method for spalling of RPC in fire are being studied extensively, such as adding fibres and coating fire insulation[13-15].

While, the full-scale RPC beams cured with $70-90^{\circ} \mathrm{C}$ steam condition performed severe thermalinduced spalling in fire tests commonly[15-17]. As a result, the sectional dimension of beams reduced and the failure mode could convert from flexural failure to shear failure for some specimens. Since the randomness of spalling and the un-integrity of cross-section of specimens, fire test study is relatively complicated after spalling occurred, moreover, fire test result could not be directly referable for further expanding research on mechanical behaviour of RPC beams in and after fire. Except for spalling, the addition of steel fibres into RPC improves thermal conductivity and reduces specific heat capacity, which are 1.5-2.0 times and 0.4-0.5 times of NSC, respectively[18]. The thermal-induced attenuation amplitudes of mechanical performance of RPC are considerably bigger than NSC at the same temperature[19]. Given the severe degradation of tensile strength of RPC in tensile region on fire-exposed side contributing to flexural capacity directly, as well as prestress and material properties loss of tendons, prestressed RPC beams have a greater risk on failure and collapse than NSC beams in fire.

This paper innovatively proposed a hot-air curing for RPC to prevent thermal-induced spalling with the similar energy consumption to steam curing. In total, eight simply supported prestressed RPC beams were prepared using $150^{\circ} \mathrm{C}$ hot-air curing. A full scale fire tests have been conducted on the beams under 
ISO 834 standard fire conditions[20]. Moreover, investigations on the effect of load ratios, cover thicknesses of tendons, bonded and unbonded tendons, and partial prestressing ratio $(P P R)$ on the behaviour of fire-exposed prestressed RPC beams were carried out. In addition, fire design specification of prestressed RPC beams was proposed. Since the prestressed RPC beams maintain good appearance integrity during this fire tests, the results of fire response of prestressed RPC beams are reasonable and referable.

\section{Experiments program}

\subsection{Design of specimens}

Eight prestressed RPC beams were designed with the cross-sectional dimensions of $250 \mathrm{~mm} \times 350 \mathrm{~mm}$ and the total length of $6500 \mathrm{~mm}$. The effective spans were $6000 \mathrm{~mm}$ for all eight tested beams. The varying parameters for the test specimens were load ratios, cover thicknesses of tendons, categories of bonded and unbonded tendons, and $P P R$, as detailed in Table 1.

Table 1 Summary of test parameters of beams

\begin{tabular}{cccccccccc}
\hline $\begin{array}{c}\text { Beam } \\
\text { designation }\end{array}$ & $C_{\mathrm{p}} / \mathrm{mm}$ & $\begin{array}{c}\text { Load } \\
\text { ratio }\end{array}$ & $P P R$ & $A_{\mathrm{p}}$ & $\begin{array}{c}f_{\mathrm{cu}} \\
/ \mathrm{MPa}\end{array}$ & $\begin{array}{c}f_{\mathrm{t}} \\
/ \mathrm{MPa}\end{array}$ & $\begin{array}{c}\text { Ultimate flexural } \\
\text { capacity } \\
/(\mathrm{kN} \cdot \mathrm{m})\end{array}$ & $\begin{array}{c}\text { Preload } \\
/ \mathrm{kN}\end{array}$ & $\begin{array}{c}\text { prestress } \\
/ \mathrm{kN}\end{array}$ \\
\hline PRPCB1 & 35 & 0.3 & 0.69 & $3 \mathrm{~b} \phi^{\mathrm{S}} 15$ & 162.94 & 11.40 & 355.76 & 96.93 & 581.72 \\
PRPCB2 & 35 & 0.5 & 0.69 & $3 \mathrm{~b} \phi^{\mathrm{S}} 15$ & 165.17 & 12.29 & 363.30 & 171.45 & 581.75 \\
PRPCB3 & 45 & 0.5 & 0.60 & $2 \mathrm{~b} \phi^{\mathrm{S}} 15$ & 158.03 & 11.16 & 287.34 & 133.87 & 387.81 \\
PRPCB4 & 45 & 0.5 & 0.69 & $3 \mathrm{~b} \phi^{\mathrm{S}} 15$ & 176.77 & 12.51 & 358.68 & 169.54 & 581.70 \\
PRPCB5 & 55 & 0.3 & 0.69 & $3 \mathrm{~b} \phi^{\mathrm{S}} 15$ & 166.42 & 12.38 & 340.30 & 92.20 & 581.73 \\
PRPCB6 & 55 & 0.5 & 0.69 & $3 \mathrm{~b} \phi^{\mathrm{S}} 15$ & 165.90 & 12.77 & 346.84 & 163.62 & 581.72 \\
UPRPCB1 & 45 & 0.5 & 0.69 & $3 \mathrm{U} \phi^{\mathrm{S}} 15$ & 160.87 & 11.65 & 354.36 & 167.38 & 581.75 \\
UPRPCB2 & 55 & 0.5 & 0.69 & $3 \mathrm{U} \phi^{\mathrm{S}} 15$ & 162.15 & 11.93 & 346.82 & 163.61 & 581.71 \\
\hline
\end{tabular}

The six bonded prestressed RPC beams were designated as PRPCB1-6, and the other two unbonded prestressed RPC beams were designated as UPRPCB1-2 respectively. $C_{\mathrm{p}}$ is the cover thickness of tendons at midspan cross-section. $f_{\text {cu }}$ and $f_{\mathrm{t}}$ are the average values of RPC cube compressive and tensile strength at ambient temperature respectively. Given the tensile force provided by RPC in tension zone, ultimate flexural capacity for beams were calculated with the method from ZHENG et al.[7]. PPR is determined as per the following the Eq. (1).

$$
P P R=A_{\mathrm{p}} \sigma_{\mathrm{p}} /\left(A_{\mathrm{p}} \sigma_{\mathrm{p}}+A_{\mathrm{s}} f_{\mathrm{y}}\right)
$$

where $\sigma_{\mathrm{p}}$ is the predicted ultimate tensile stress of tendons under ultimate flexural capacity, $f_{\mathrm{y}}$ is the measured yield strength of longitudinal rebars at ambient temperature, $A_{\mathrm{p}}$ and $A_{\mathrm{s}}$ are the area of tendons and the longitudinal rebars in tension zone, respectively.

Tendons were configured to be parabolic profile and to extend horizontally along neutral axis at beam supports. The horizontal distance between contra-flexural points and supports were maintained as 0.15 
times the effective span. The cover thickness of longitudinal rebars $(C)$ were $25 \mathrm{~mm}$ for the all beams. As examples, the details of PRPCB1 and UPRPCB1 are shown in Fig. 1, where the numbers after tendons profile are the distance between the centreline of tendons and the bottom surface of beams at mid-span and at contra-flexural points respectively.
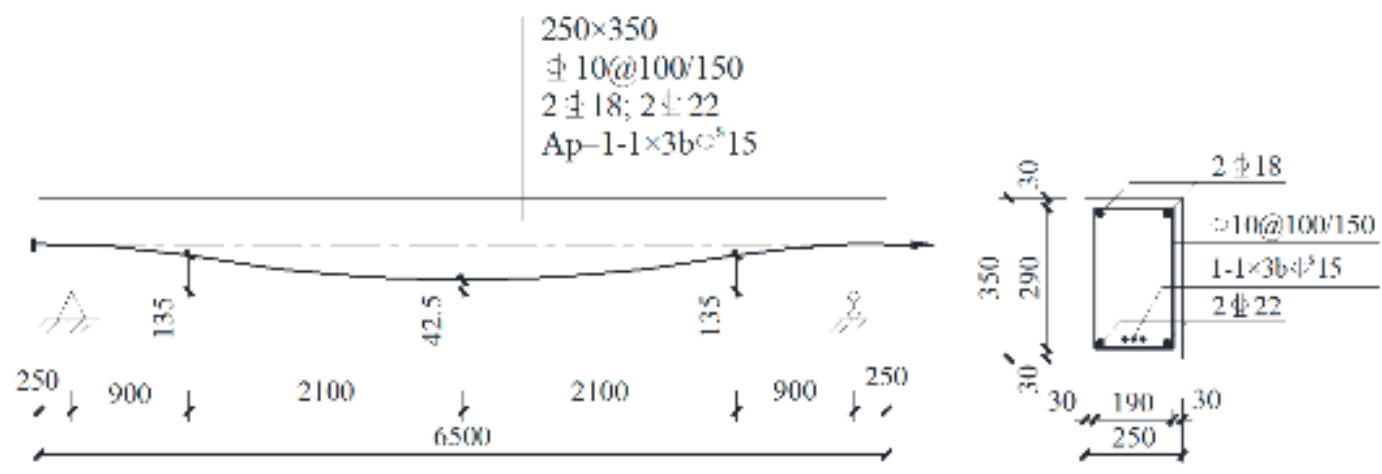

(a) PRPCB1
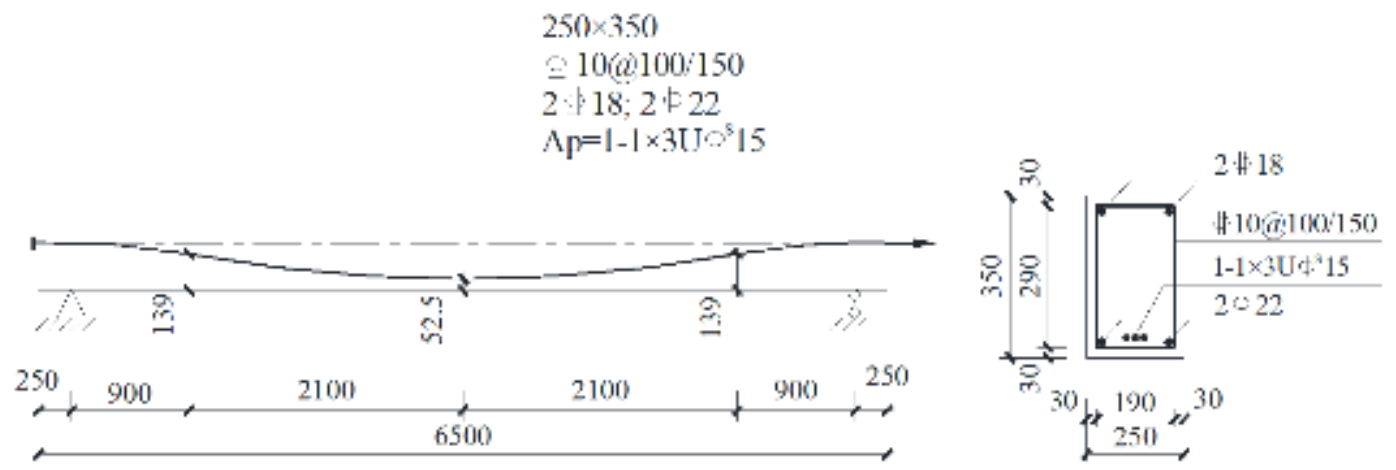

(b) UPRPCB1

Fig.1 Details of tested beams (all dimensions in $\mathrm{mm}$ )

The tendons were $15.2 \mathrm{~mm}$ nominal diameter low relaxation seven-wire mono-strand tendons with a tensile strength of $1860 \mathrm{MPa}$. Anchor systems were used BM15-3 clip anchors, and flat metallic ducts $(65 \mathrm{~mm} \times 25 \mathrm{~mm})$ were adopt to ensure the same cover thickness for tendons. All specimens consisted of two $\$ 18 \mathrm{~mm}$ and two $\$ 22 \mathrm{~mm}$ longitudinal reinforcements at compression and tension faces, respectively. The $\$ 10 \mathrm{~mm}$ rebars were used as stirrups, with a distribution spacing of $100 \mathrm{~mm}$ between supports and loading points, $150 \mathrm{~mm}$ between the two loading points of the beams. The strength index of reinforcement is given in Table 2.

Table 2 Strength index of reinforcement

\begin{tabular}{cccc}
\hline type & Yield strength/MPa & $\begin{array}{c}\text { Ultimate strength } \\
/ \mathrm{MPa}\end{array}$ & $\begin{array}{c}\text { Conditional yield } \\
\text { strength/MPa }\end{array}$ \\
\hline$\$ 10$ & 487.33 & 657.49 & $/$ \\
$\$ 18$ & 485.90 & 644.83 & $/$ \\
$\$ 22$ & 484.51 & 660.12 & $/$ \\
$\phi^{\mathrm{S}} 15$ & $/$ & 1902.94 & 1455.07 \\
\hline
\end{tabular}




\subsection{Materials and mix proportion}

The RPC components were detailed as follows: Cement: P.O 52.5 Portland cement; Silica Fume: $92.17 \% \mathrm{SiO}_{2}$ content and the specific surface area of $24200 \mathrm{~m}^{2} / \mathrm{kg} ; \mathrm{S} 75$ slag powder: the specific surface area of $450 \mathrm{~m}^{2} / \mathrm{kg}$; Fly ash: specific surface area of $600 \mathrm{~m}^{2} / \mathrm{kg}$; Fibres: type I flat-straight coppered steel fibres with the length of $13 \mathrm{~mm}$ and the equivalent diameter of $0.22 \mathrm{~mm}$; Superplasticizer: liquid polycarboxylate with $40 \%$ solid content. To lower the cost of production and extend application, natural fine river sand (fineness modulus of 1.92 and particle size range 1.0$3.0 \mathrm{~mm}$ ) was utilized to replace quartz as fine aggregate. The mix proportion of RPC is shown in Table 3 , the corresponding compressive and tensile strength were listed in Table 1.

Table 3 RPC Mix proportion

\begin{tabular}{ccccccc}
\hline $\begin{array}{c}\text { water-binder } \\
\text { ratio }\end{array}$ & cement & Silica fume & slag & fly ash & fine aggregate Superplasticizer & $\begin{array}{c}\text { Steel fibre } \\
\text { (by volume) }\end{array}$ \\
\hline 0.2 & 1 & 0.3 & 0.2 & 0.2 & 1.2 & 0.04 \\
\hline
\end{tabular}

Annotation:

1. The steel fibre proportion is the volume-based ratio of steel fibres to RPC matrix.

2. Water-binder ratio is the weight-based ratio of water to cementitious materials (cement, silica fume, slag and fly ash).

3. The proportions of the rest of components are all the weight-based ratio to cement.

\subsection{Preparation and hot-air curing}

The preparation of RPC was staged as follows: Firstly, cementitious materials (cement, silica fume, slag, fly ash and sand) were loaded into high-powder mixer in order and dry mixed for 5 minutes to ensure the uniformity. Secondly, superplasticizer and water were added and mixed for 3 minutes until the matrix showed a good fluidity. Finally, the steel fibres were sprinkled evenly and mixed for 6 minutes to ensure uniform distribution. After that, the fresh mixture was cast into the moulds. De-molding was undertaken after hardening under ambience condition for three days.

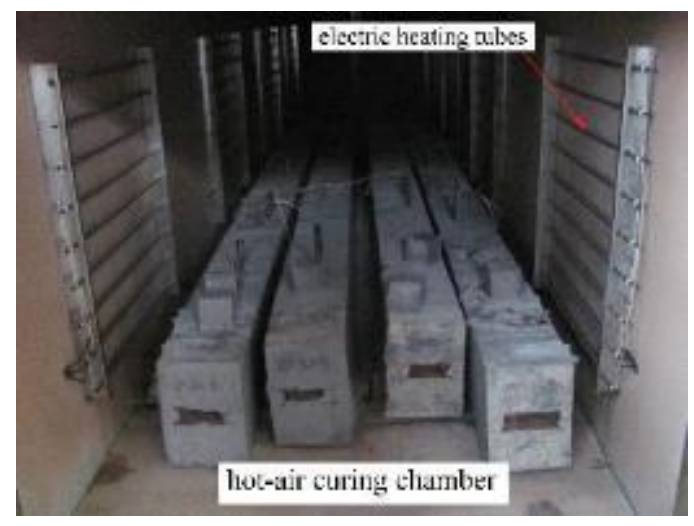

Fig. 2 hot-air curing 
Specimens subsequently were placed into the hot-air curing chamber at $45^{\circ} \mathrm{C}$ for 24 hours, and then gradually heated in the rate of $30^{\circ} \mathrm{C} / \mathrm{h}$ to $150^{\circ} \mathrm{C}$ for 24 hours. Fig. 2 shows the hot-air curing chamber, with the energy consumption of this hot-air curing regime is approximately equal to 70 $90^{\circ} \mathrm{C}$ steam curing regime. After natural cooling, the tendons were threaded through the prearranged ducts and tensioned to $0.75 f_{\mathrm{ptk}}\left(f_{\mathrm{ptk}}\right.$ is standard value of ultimate strength of tendons $)$ followed by anchoring. For the bonded prestressed RPC beams, grouting was conducted using the indicated mixing ratio of RPC immediately after anchoring. All the specimens were then placed in ambience condition for 28 days for the fire tests.

\subsection{Test setup}

The fire tests were conducted with the large-scale fire furnace at Shandong Jianzhu University. For satisfying the test requirements, the furnace was reformed to the dimension of $6.0 \mathrm{~m} \times 5.0 \mathrm{~m} \times 1.5 \mathrm{~m}$. The configuration of fire furnace was shown in Fig. 3.

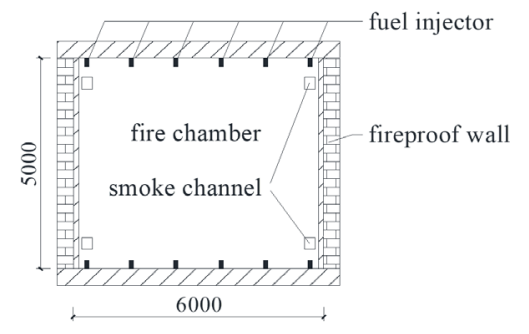

(a) Test furnace (plan view)

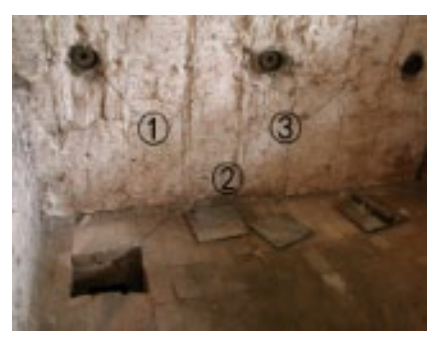

(b) Furnace assembly

Fig. 3 Configuration of the fire test furnace

(1)— fuel injector, (2) - smoke channel, (3)— fireproof wall

Concrete fireproof slab and fireproof fibres were utilized on the top of the furnace to seal and to prevent fire spreading, ensuring the beams were exposed to fire on three sides. Fig. 4 shows the fire test setup. Each group comprised four specimens with similar predicted fire resistance. The four beams in a group were tested simultaneously following the arrangement shown in Fig. 5. The PRPCB1-4 were the first batch to be tested, and the PRPCB5-6 as well as UPRPCB1-2 were the second batch. 


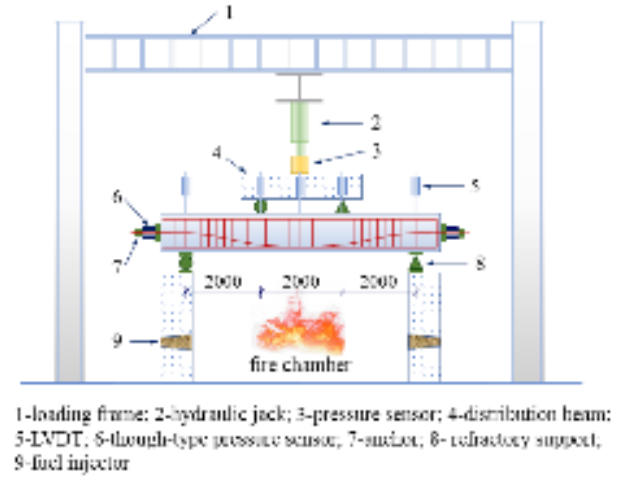

(a) Test setup sketch

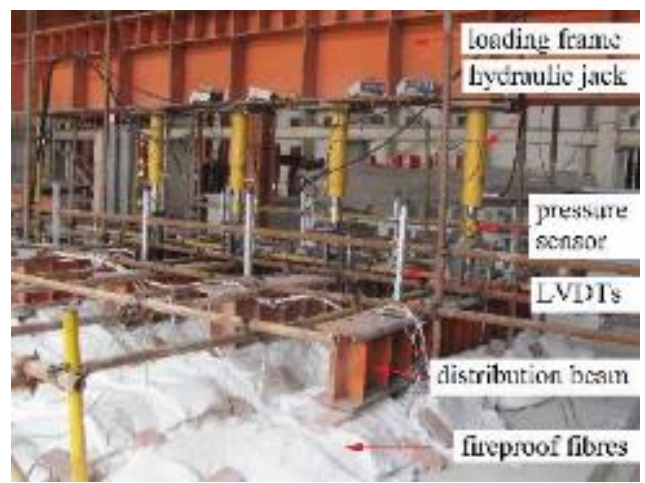

(b) lab view of test setup

Fig. 4 Test setup

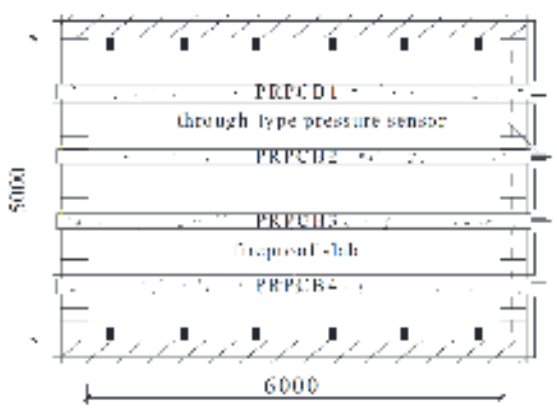

(a) Layout (plan view)

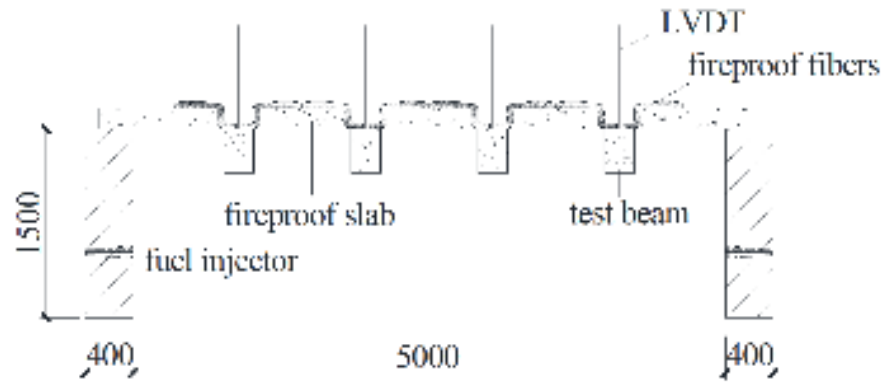

(b) Layout (elevation)

Fig. 5 Group layout of tested beams

2.5 Fire test procedure

The tested beams were subjected to a static constant load and exposed to fire on three sides (the bottom side and two lateral sides) under simply supported conditions. The loads were applied on trisected points of the beam with a hydraulic jack (500mm stroke capacity) to the corresponding load ratios. The furnace temperature was increased followed the ISO 834 standard fire curve.

\subsection{Measurement details}

The temperatures at measuring points in beams, mid-span deflections and effective prestresses were measured during the fire tests.

The temperatures in beams and on tendons as well as longitudinal rebars were measured by thermocouples. 31 thermocouples were embedded in each tested beam detailed in Fig. 6(a), where $\mathrm{P} 1, \mathrm{P} 2$ were the measuring points on the prestressing tendon, 8 was the measuring point on the longitudinal rebar, and other serial numbers were the measuring points of RPC. For eliminating the position error induced by installation and casting, the thermocouples were cast as temperature sensor using the same mixture of RPC as the tested beams prior to installation. 


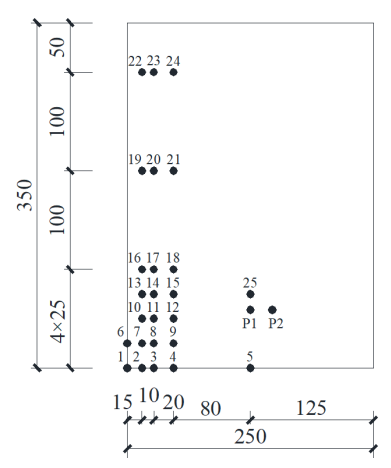

(a) Positions of thermocouples

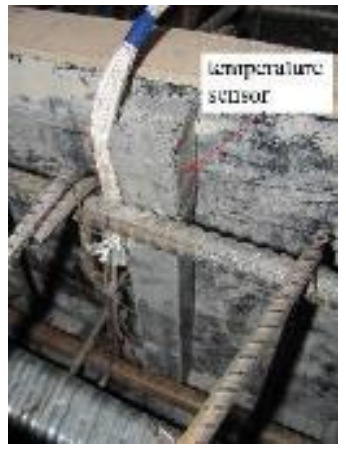

(b) temperature sensor

Fig. 6 Measurement of temperature

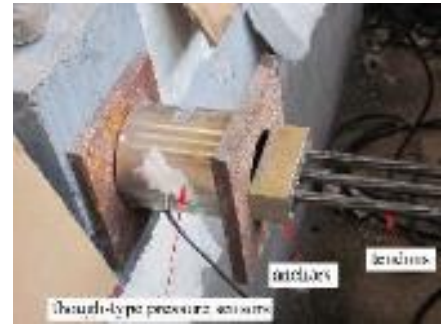

(a) though-type pressure sensors

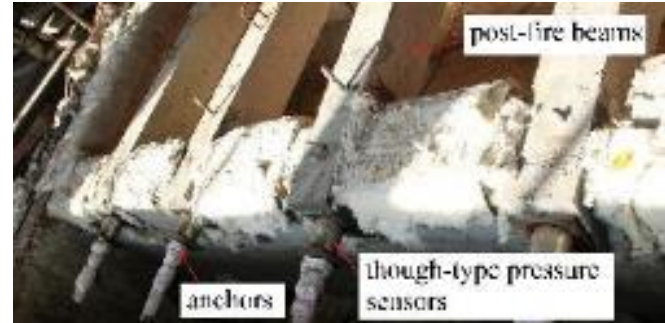

(b) post-fire view

Fig.7 Measurement of effective prestress

The mid-span deflections of the specimens were measured by linear various displacement transducers (LVDTs) during fire tests. The LVDTs were installed at the mid-span, at the loading points and the supports of each beam, with the corresponding ranges were $\pm 250 \mathrm{~mm}, \pm 250 \mathrm{~mm}$ and $\pm 100 \mathrm{~mm}$, respectively. The temperatures and the deflections were recorded using Agilent 34980A. The effective prestresses were measured by the though-type pressure sensors installed between beam ends and anchors. The measured data was then recorded with a static strain acquisition instrument, DH3816. All the measurements were recorded simultaneously every $15 \mathrm{~s}$.

\section{Test results and external performance after fire}

\subsection{Observation}

In the first batch of fire test, no burst noise nor obvious deformation were observed during the early period of fire exposure. The mid span deflections increased slowly after exposure fire for 70 mins. Through 100 mins of fire test, the rise rate of deflection increased rapidly for beams PRPCB2 to PRPCB4. At 112 mins, loud sound was generated by PRPCB2, longitudinal rebars fractured accompanying with a rapidly increase in mid-span deflection. Immediately after, the mid-span deflection increased rapidly to over the deflection limitation $(L / 20$, where $L$ is the effective span)[21], $300 \mathrm{~mm}$, reaching its fire resistance. To inhibit fire spreading, PRPCB2 were unloaded. In the postfire tests observation, the slip between tendons and surrounding RPC was observed at the maximum 
crack on the bottom of PRPCB2. It can be attributed to the local failure of interlocking effect and tendons necking-down. After 119 mins and 135 mins of fire exposure, the mid-span deflection of PRPCB4 and PRPCB3 increased rapidly over 300mm respectively, thereafter, the two beams were unloaded. For PRPCB1, no obvious failures were observed until unloading after $150 \mathrm{~min}$ of test, and the first batch of test terminated.

In the second batch of fire test, the similar phenomena were observed as the first batch of fire test during the early stage. After 79 mins of fire exposure, smoke was observed from the ends of UPRPCB1, accompanying with sizzle sounds and yellow oily fluid as shown in Fig. 8. After 91 mins of fire exposure, the similar phenomena occurred in UPRPCB2. The composition of plastic ducts of unbonded tendons is high-density polyethylene, with a melting point temperature of $200-250^{\circ} \mathrm{C}$, and a burning point temperature of $340^{\circ} \mathrm{C}$. After temperature upper to $340^{\circ} \mathrm{C}$, the plastic ducts burned insufficiently because of the lack of oxygen in prefabricated tunnel. Hence then, the smoke was generated as vaporization product of plastic ducts. The yellow oily fluid was the melting grease of unbonded tendons at elevated temperature, flowing out as the pressure of tunnel increased by plastic ducts vaporization.

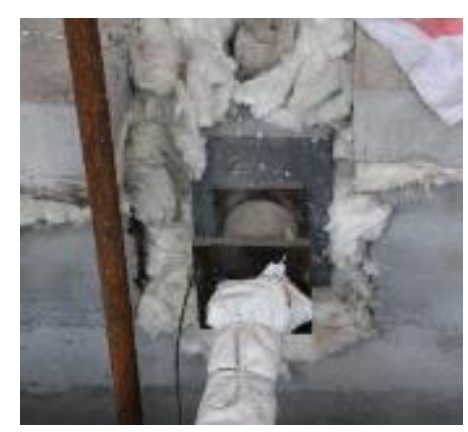

(a) smoke

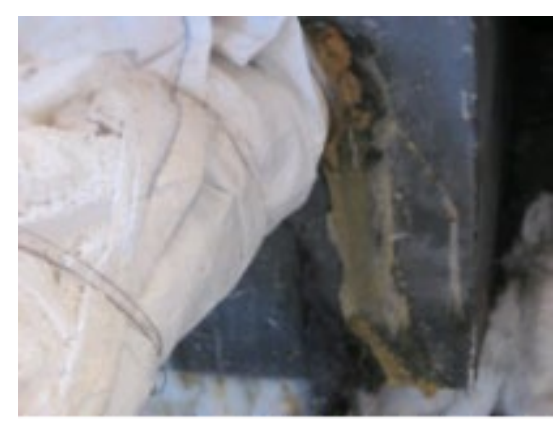

(b) melting grease

Fig. 8 Observation of unbonded tendons in fire tests

Through 120 mins of exposure, continuous sounds were generated from UPRPCB1, resulting from the sliding frictions between the unbonded prestressing tendons and the ducts. The rise rate of mid-span deflection for UPRPCB1 increased visibly, revealing that it could not bear the imposed load anymore; thereby, it was unloaded. At 132 mins and 154 mins of fire exposure, UPRPCB2 and PRPCB6 reached the limited deflection and were unloaded respectively. For PRPCB5, no obvious failure occurred after 160 mins of fire exposure then unloading, the second batch of fire test terminated. For all the tests processes, there were no water vapor and water accumulation during the fire test. 
Fig. 9(a)-(h) shows the observations of beams after fire exposure. The obviously residual deflections and cracks were observed in the specimens which reached fire resistance in the tests. It can be seen that the colour of bottom surface and two lateral sides was yellow-pinked, and the steel fibres on surface were dark blue; the colour near supports was greyish white or tan, the colour details on the surface of beams are shown in Fig.10. All the eight beams flexural cracks to varying extents were observed. Six beams were damaged as flexure failure mechanism, and the main cracks concentrated around mid-span. During the natural cooling process, partial of the capacities of RPC and tendons recovered, and the beams also presented a recovering trend in deflection. PRPCB1 and PRPCB6 regained more due to the lighter thermal-induced damages, and PRPCB6 bended upward for $32 \mathrm{~mm}$.

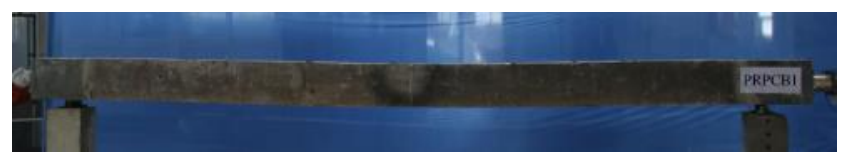

(a) PRPCB1

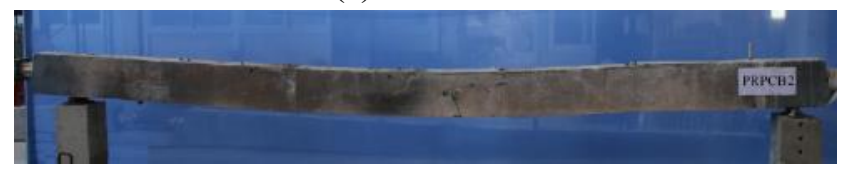

(b) PRPCB2

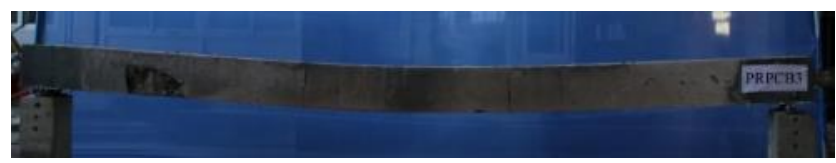

(c) PRPCB3

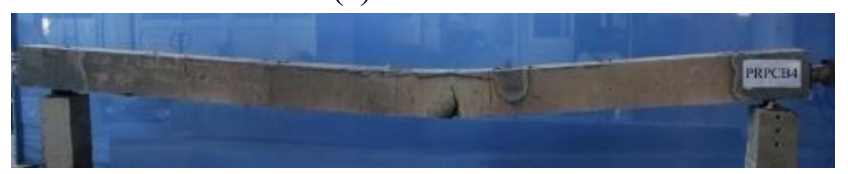

(d) PRPCB4

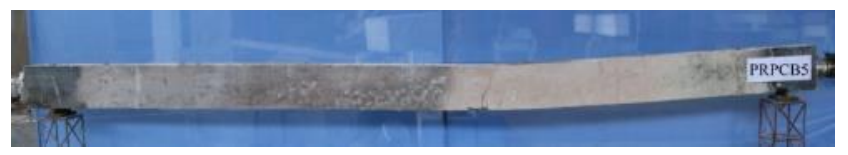

(e) PRPCB5

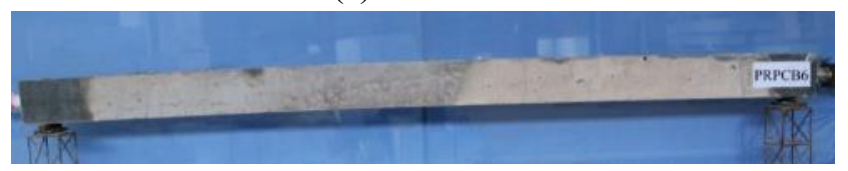

(f) PRPCB6

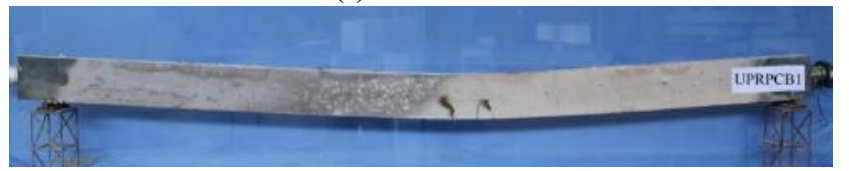

(g) UPRPCB1 


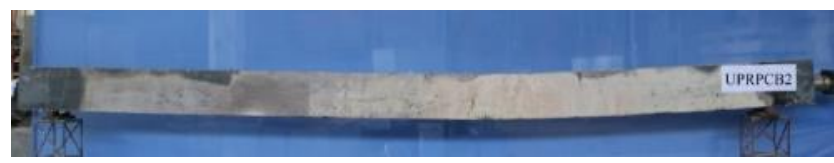

(h) UPRPCB2

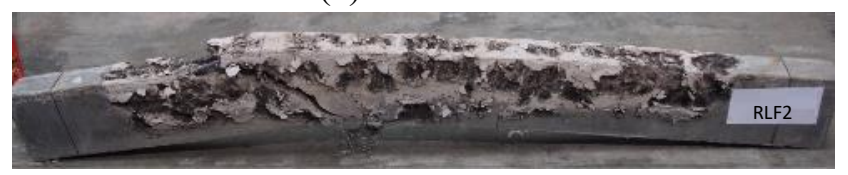

(i) RLF2[16], [17]

Fig. 9 Observations of beams after fire tests

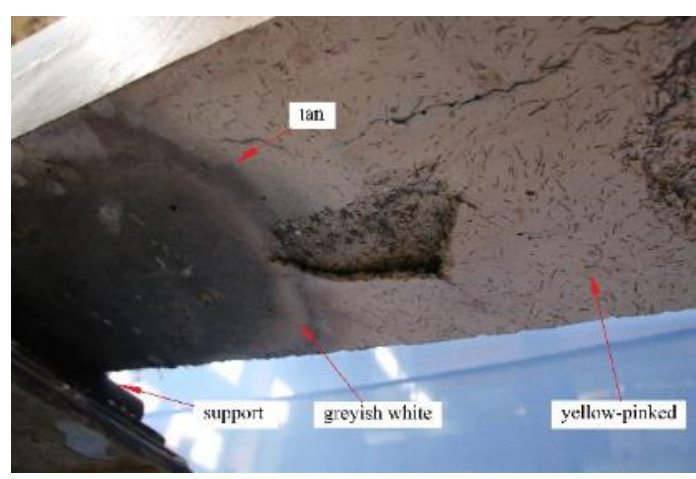

Fig. 10 Colour details of beams after fire tests

Fig. 9(i) shows the thermal-induced spalling of beams from Kahanji and Abid [16], [17], cured with $90^{\circ} \mathrm{C}$ steam condition as common curing method for RPC currently. It can be found that serious spalling occurred, as a result, mechanical properties and failure modes of beams were changed completely. The risk of RPC structural members in fire significantly increases due to thermal-induced spalling. That might be one of the main reasons for hindering more widely used of RPC, excepting for the expensive material compositions as another reason. In this test, a hot-air curing condition was innovatively proposed to cure the beams. Compared with $90^{\circ} \mathrm{C}$ steam curing, the post-fire tests observation shows that only slight spalling occurred on the beams cured with $150^{\circ} \mathrm{C}$ hot-air condition. The spalling-damaged areas accounted for approximately $2.76 \%$ of the whole fire-exposed areas, and the depth of spalling ranged from $3 \mathrm{~mm}$ to $12 \mathrm{~mm}$. The most spalling occurred near the supports on bottom surface and two lateral sides. It can be explained by the higher ratio of compressive stress (or the lower ratio of tensile stress) and the larger thermal gradients in the region of furnace chamber near fireproof wall. In the spalling-damaged region, the steel fibres outcropped from the RPC were randomly distributed in three dimensions, providing the effect of bridging, shown in Fig. 11. 


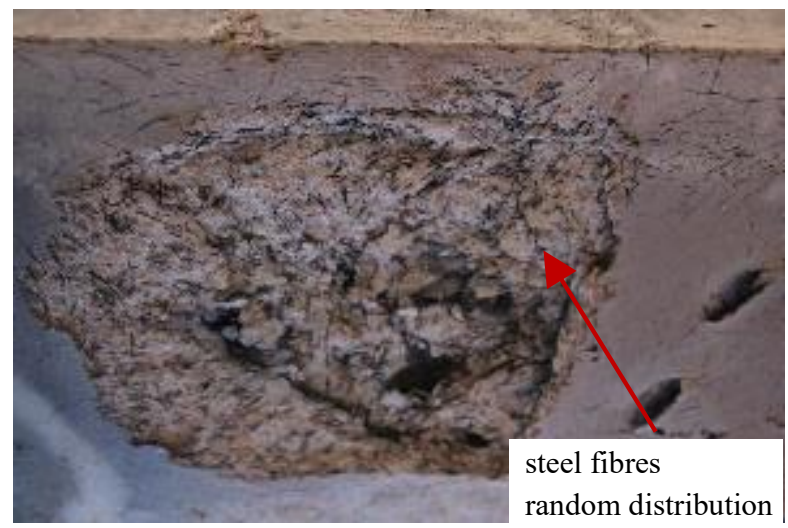

Fig. 11 Spalling in the specimens

The spalling of RPC is vulnerable to thermal-induced stress gradient and interior vapor pressure. The good thermal conductivity of steel fibres improves the performance of RPC in heat-conducting. Compared with NSC and high strength concrete (HSC) in the same fire condition, RPC possesses lower thermal-induced gradient, resulting in lower thermal stress. Furthermore, the addition of steel fibres improved the tensile strength of RPC. Additionally, the bridging effect from three dimensions randomly distributed steel fibres would mitigate thermal expansion, reducing the risk of random cracks effectively[22].

Moreover, free water in RPC evaporated to form vapours at elevated temperature. These vapours condensed to form a saturated water layer when diffusing to interior of RPC at high heating rates. At temperatures ranged from $350-500^{\circ} \mathrm{C}$, water vapours outside the saturated water layer increased pore pressures, attributing to low permeability and saturated the water layer[23]. Therefore, higher moisture contents imply higher pore pressures. Once pore pressures had exceeded the tensile strength of RPC, spalling occurred. By utilizing the hot-air curing at $150^{\circ} \mathrm{C}$, most of the free water inside RPC can be consumed by hydrating and pozzolanic reactions, and the rest of the water would escape in the form of water vapours; reducing the vapor pressures significantly. Consequently, the slight spalling and the good integrity of the specimens after the fire tests can be explained by the reasons above. Compared with steam curing, hot-air curing is an effective way to prevent thermal-induced spalling of RPC with high stress level in high heating-rate fire environment.

\subsection{Temperature field}

The comparison of the measured furnace temperature with the ISO834 standard fire curve is shown in Figure 12. It can be seen that the measured furnace temperature agreed well with the ISO834 standard fire curve. 


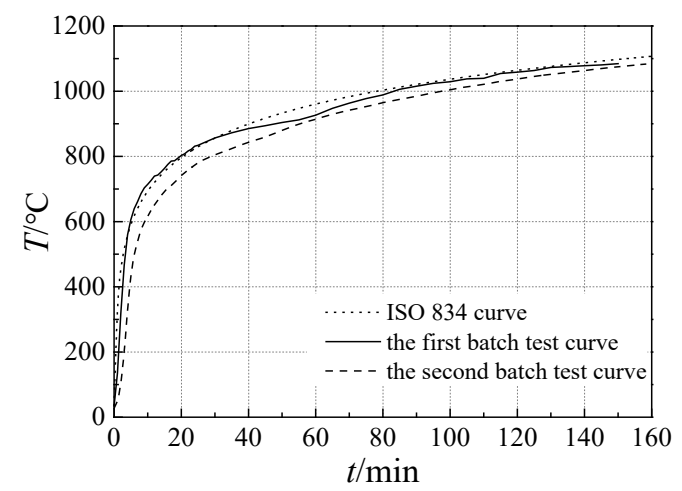

Fig. 12 Temperatures-fire curves of fire furnace

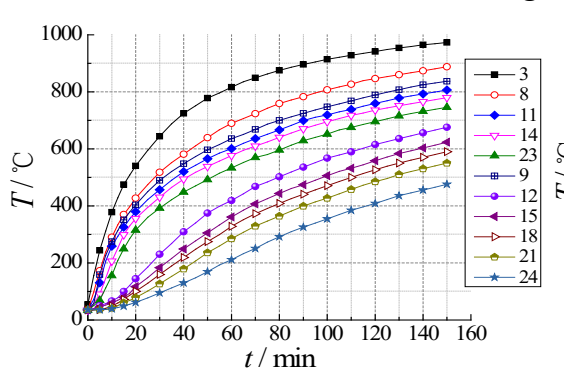

(a) PRPCB1

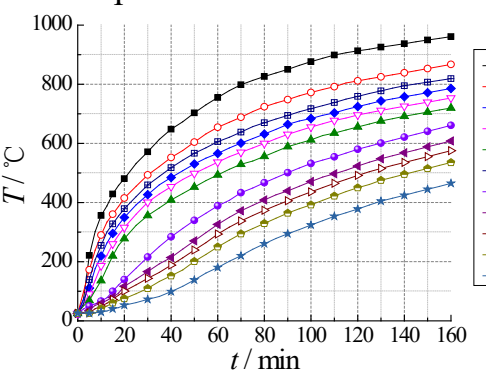

(b) UPRPCB1
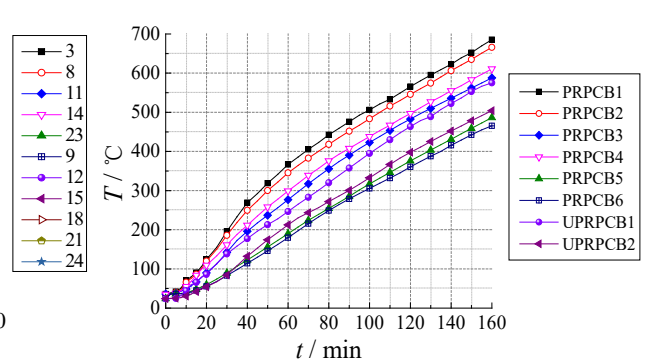

(c) tendons

Fig. 13 Temperatures-fire curves of tested beams

The temperature versus time curves of the measuring points inside PRPCB1 and UPRPCB1 are separately illustrated in Fig. 13(a) and (b). It can be seen that the temperatures inside the specimens grew nonlinearly with the increase of fire-exposed time. Since RPC is a thermal-inert material, the transfer law of transient heat followed the quadratic parabolic nonlinear equation, resulting in the non-uniform temperature distribution. More specifically, the closer to the fire-exposed side, the higher temperature gradient and temperature rise rate, resulting in a higher convexity of the curve. Because of the uniform heating scheme, the temperature versus time curves of all tested beams show the similar trend. The temperatures at the measuring points in different specimens showed high-similarity. For PRPCB1 and UPRPCB1, the temperature differences between point 8 and point 12 are $257^{\circ} \mathrm{C}$ and $243^{\circ} \mathrm{C}$ severely after 60 mins fire exposure. It is worth noting that the temperatures difference for NSC is $312^{\circ} \mathrm{C}[24]$ under the same condition. It can be explained that the addition of steel fibres improves the thermal conductivity of RPC and thereby lower the temperature gradients.

\subsection{Mid-span deflection}

The beam deflections in fire exposure results from the combined effects of loadings and temperatures. The incremental deflection of the tested beams is the combination of the three effects: Firstly, the beam deflected upward due to the prestress, while it shows downward deflections trend because of the applied loads; Secondly, during the heating process, the expansion of fire-exposed sides results in downward 
deflections, simultaneously, the thermal-induced axial expansion strengthened the effect of prestress, leading to trend of upward deflection; Thirdly, the thermal-induced degradation of elastic modulus and strength in RPC and reinforcement aggravated the trend of downward deflections in beams.

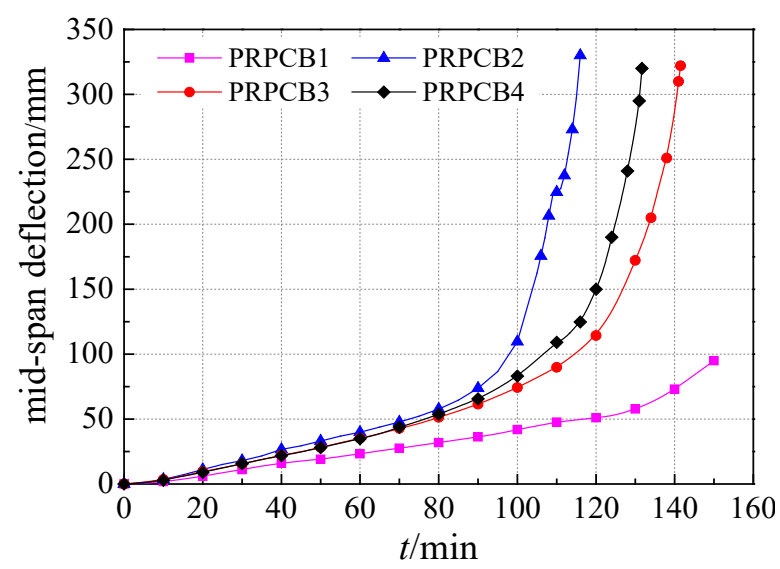

(a) the first batch test

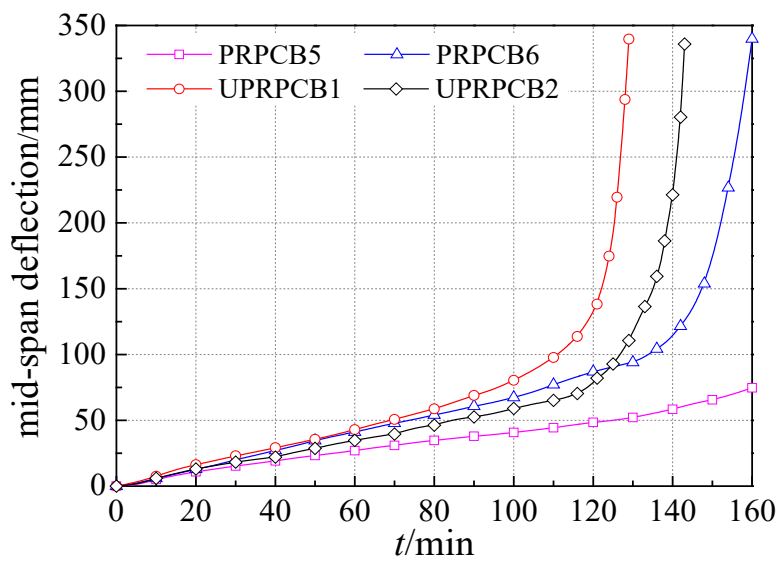

(b) the second batch test

Fig. 14 Mid-span deflection-time curves of tested beams

The mid-span deflection versus time curve of specimens are plotted in Figs. 14 (a) and (b). The variation of mid-span incremental deflections can be divided into three stages:

1) During the early stage, the mid-span deflection increased slowly. The temperature of bonded prestressing tendons (within $400^{\circ} \mathrm{C}$ ), unbonded prestressing tendons (within $350^{\circ} \mathrm{C}$ ), and $\mathrm{RPC}$ inside the cover thickness of tendons (within $500^{\circ} \mathrm{C}$ ) were relatively low, resulting in the slight deterioration of the mechanical properties of RPC and reinforcement. This stage lasted for 70 mins for PRPCB2 and 90 mins for UPRPCB1 from the beginning of heating.

2) During the second stage, the mid-span deflection increased significantly. In this stage, the temperatures in bonded prestressing tendons increased to $400-500^{\circ} \mathrm{C}$, and the elastic modulus and tensile strength in reinforcing rebars and RPC (bottom side) significantly degraded. It has been proved that when the temperature increases over $400^{\circ} \mathrm{C}$, the elastic modulus of reinforcement will reduce to $70 \%$, and tensile strengths will decrease to $60 \%$ (rebars) and $40 \%$ (tendons) as compared to those at ambient temperature $[25]$.

Moreover, the stress relaxation and creep of tendons are obvious in high temperatures and stress levels situation. Under the stress level of 0.75 and 2 mins fire exposure at $300^{\circ} \mathrm{C}$, the stress relaxation and creep can reach $450 \mathrm{MPa}$ and $1.5 \times 10^{4} \mu \varepsilon$, leading to significant prestress loss [26], [27]. For unbonded prestressed beams, the transferring of prestress loss to the global beam caused larger deflections than bonded prestressed beams. For boned prestressed beams, the reliable bonding effect between tendons and surrounding RPC prevents the transferring of severe prestress relaxation and creep to the global beam. This 
stage lasted from 70 mins to $100 \mathrm{mins}$ for PRPCB2 and 90min to $117 \mathrm{~min}$ for UPRPCB1.

3) During the third stage, the mid-span deflection increased to limited deflection with a high-speed. In this stage, the temperatures in bonded prestressed tendons exceeded $500^{\circ} \mathrm{C}$, the elastic modulus of reinforcing rebars and prestressing tendons reduced approximately to $50 \%$, and tensile strength reduced nearly to $50 \%$ and $20 \%$ respectively comparing with equivalent in ambient temperature. The tensile strength of hot air curing RPC was $25 \%$ lower than that of ambient temperature curing specimen, and simarly, the compressive strength of RPC declined as well. Therefore, flexural capacity degraded closely to the imposed load-induced moments, and the beam could not bear the applied loads anymore accompanying with the sharp increase in mid-span deflections to $300 \mathrm{~mm}$.

For unbonded prestressing tendons, after the fire exposure $400^{\circ} \mathrm{C}$ for 20 mins, thermal-induced prestress relaxation and creep are $850 \mathrm{MPa}$ and $3.0 \times 10^{4} \mu \varepsilon$, separately, and loss of prestress exceeds $80 \%$. The elongation of unbonded prestressing tendons caused by softening and creep in elevated temperatures contributes to the sharp growth of mid-span deflections. When the temperature exceeds $450^{\circ} \mathrm{C}$, the unbonded prestressed beams reached the deflection limitation representing the fire endurance.

\subsection{Effective prestresses}

Fig. 15 shows the effective prestress versus time curves of the eight tested beams. It can be found that the effective prestress at the end of bonded prestressed beams had no evident change. Since the parabolic profile of prestressed tendons inner specimens, $C_{\mathrm{p}}$ was changing along the longitudinal direction. Especially in the region from contra-flexural point to support point, $C_{\mathrm{p}}$ was not less than $135 \mathrm{~mm}$, with a highest temperature on tendons of $262^{\circ} \mathrm{C}$. Considering the mechanical performance deteriorated slightly as temperature blow $300^{\circ} \mathrm{C}$, the bonding between tendons and surrounding RPC was stable.

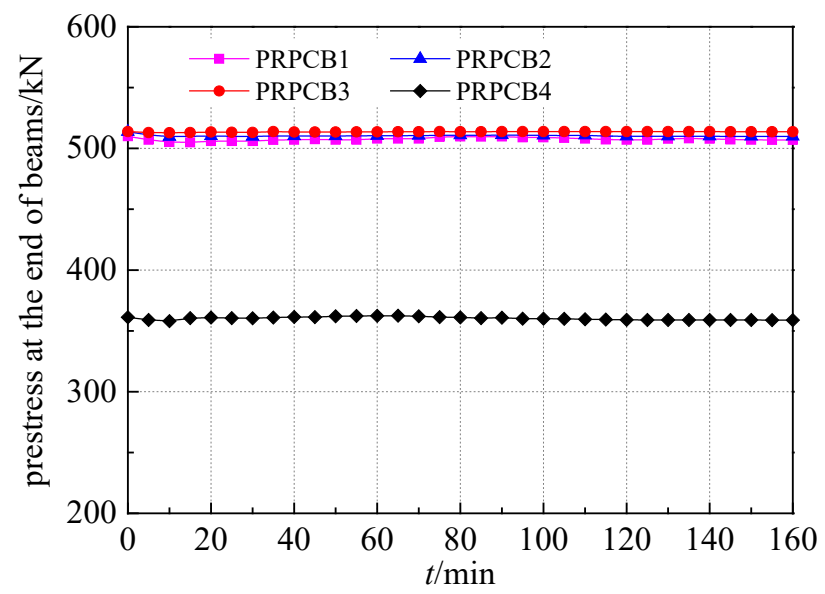

(a) the first batch test

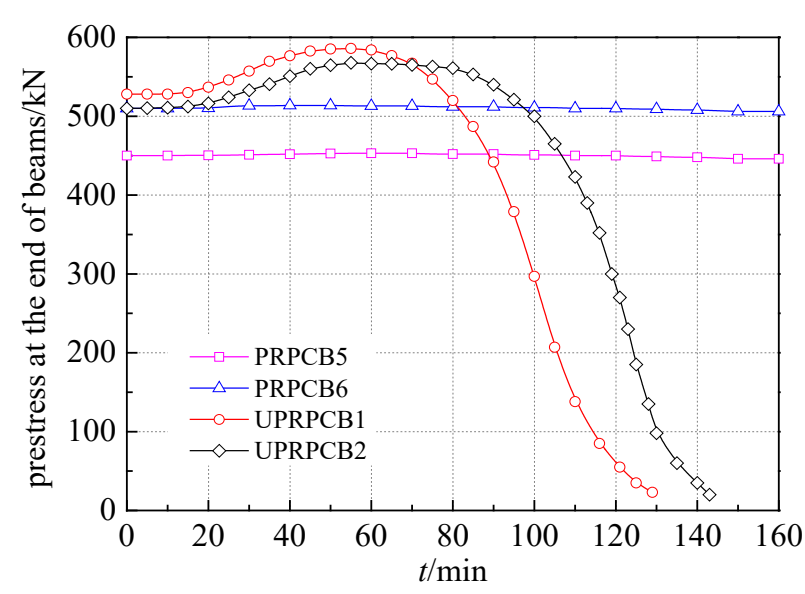

(b) the second batch test

Fig. 15 Changes of effective prestress of tendons with temperature

Tendons at mid-span region were closest to the bottom surface, which temperature versus time curves 
were shown in Figure 13(c). When temperatures were higher than $300^{\circ} \mathrm{C}$, prestress losses and creeps grew rapidly so that prestress levels reduced. After smashing and removing the lateral RPC, it was found that no bond failure and slip occurred between tendons and RPC excepting in local cracked regions; which indicated that bond coupling was well for bonded PRPCB exposed to fire, and almost no prestress losses transferred towards beam ends.

The effective prestress versus time curves of tendons in UPRPCB1 and UPRPCB2 are shown in Fig. 15(b). It can be found that the change of effective prestress with time contains ascending and descending stages. In the initial and mid-term of the test (ascending part), specimens performed tendency of full-scale expansion and downward deflection in condition that bottom and sides exposed to fire. Moreover, stiffness degenerated and deflection increased of specimens due to mechanical performance reducing at elevated temperature. The effective prestress increased significantly attributing to the two above-mentioned effects. In the ascending part, the stress increments were obviously higher than the stress decrements caused by stress relaxation and creep of tendons. In this stage, from igniting to $50 \mathrm{mins}$ and $70 \mathrm{mins}$ for UPRPCB1 and UPRPCB2, prestresses increased by $35.8 \mathrm{kN}$ and $30.2 \mathrm{kN}$ separately, accounting for approximately $7 \%$ of their original effective prestresses.

In the late-term of the test (descending part), the temperatures of tendons upper $300^{\circ} \mathrm{C}$ brought considerable prestress loss by means of stress relaxation, creep and decreasing elastic modulus. Prestress loss were higher than the stress increments causing by expansion and downward deflection of beams, resulting in effective prestress degeneration. With the increasing temperature, the effective prestress decreased continually to $20 \mathrm{kN}$ till the beams failed in fire.

Compared with UPRPCB1, the effective prestress attenuation of UPRPCB2 was obviously larger with the reason that the cover thickness of UPRPC2 was larger than UPRPCB1. Especially in the late-term of the test, the effective prestress of UPRPC2 was $130-172 \mathrm{kN}$ higher than UPRPCB1, with a temperature difference of $100-185^{\circ} \mathrm{C}$. It can be found that the longer the beams exposed to fire, the greater the effective prestress decreased. The fire test results indicated that it was an effective way by increasing the cover thickness to retard the effective prestress loss and to improve the fire resistance of unbonded prestressed beams.

3.5 Cracking patterns and failure modes

The cracks, spalling and crushed RPC zone of tested beams are shown in Fig. 16, where the shade areas indicate spalling, and the numbers in parentheses is the depth of spalling; the numbers follow by $h=$ 
indicate the height of crushed RPC zone; Z represents tensioning end; A, B are respectively the two lateral sides.

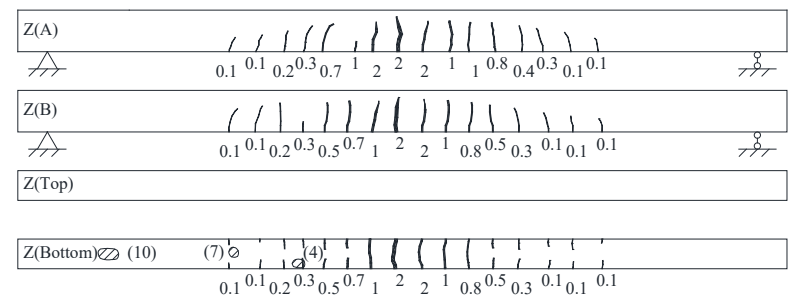

(a) PRPCB1

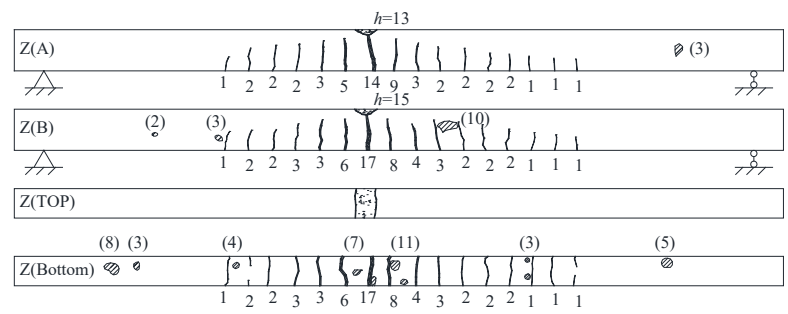

(b) PRPCB2

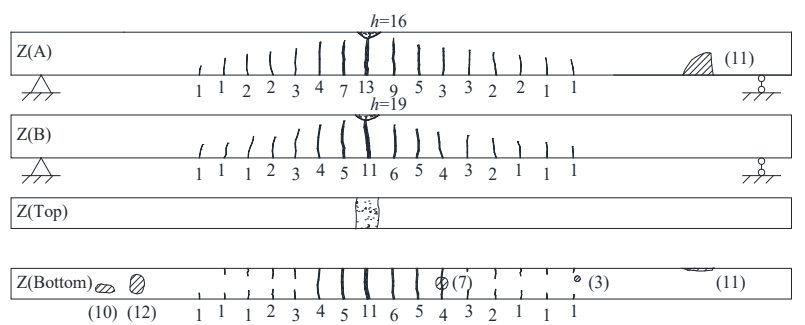

(c) PRPCB3

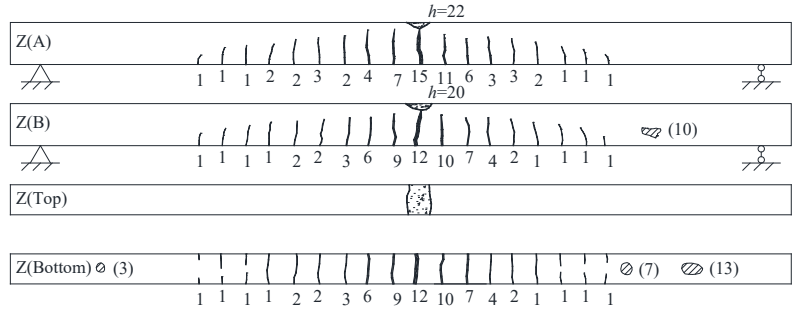

(d) PRPCB4

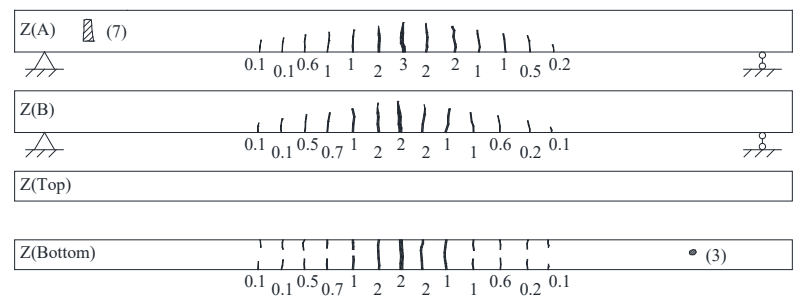

(e) PRPCB5

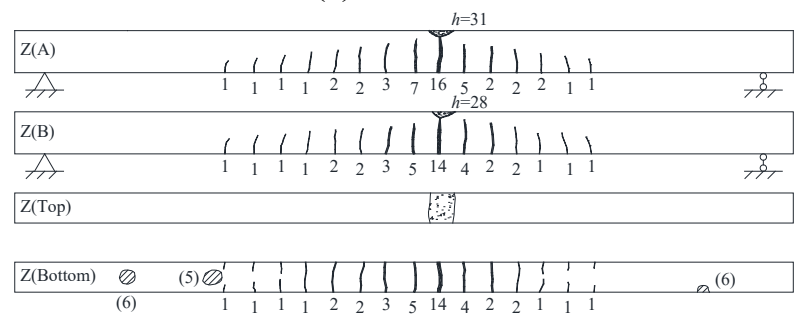

(f) PRPCB6 


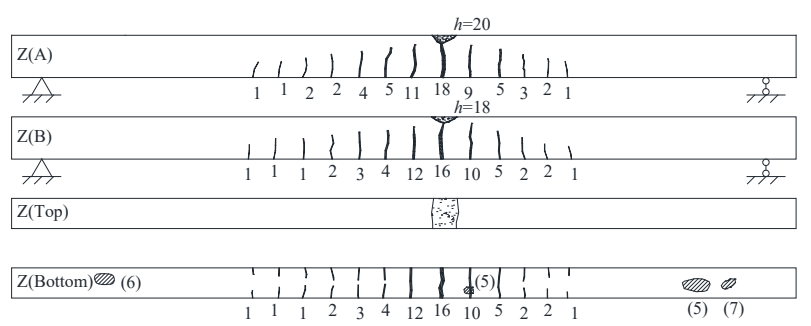

(g) UPRPCB1

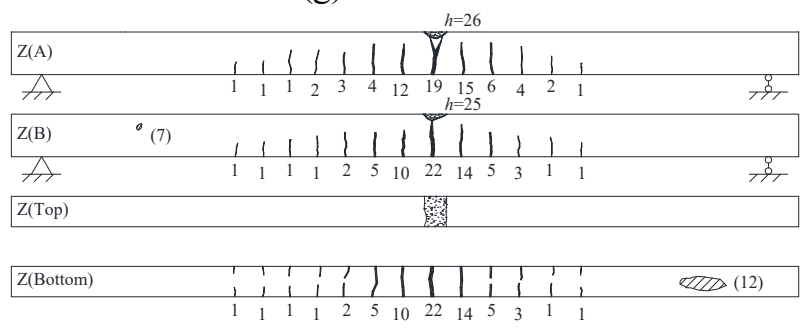

(h) UPRPCB2

Fig.16 Crack patterns, spalling distribution and crushed RPC zone of specimens

Several vertical cracks were observed on the surface of the test beams, and the main crack occurred in the pure-bending segment near the mid-span. In the region of the main cracks, the steel fibres pulled out were in dark blue, and the necking-down tendons were observed as well. The generation of wide cracks in the beams can cause tendons and longitudinal rebars exposed to fire directly, it is seriously unfavourable for fire resistance and accelerate fail in fire. The height of crushed RPC zones on the top of the beams, 14$29.5 \mathrm{~mm}$, was less than the designed height of compression zone at ambient temperature $(52.5-70.0 \mathrm{~mm})$. The degradation in tensile strength of the longitudinal rebars and RPC in tension zones were relatively higher at elevated temperatures.

Fig.17 shows typical failure mode of tested beams. RPC in compression zones suffered a relatively lower temperature and a relatively lighter deterioration of mechanical properties. The post-fire test observation indicate that the failure of prestressed RPC beams was driven by direct fire exposure and fracture of tendons and longitudinal rebars after generation of significantly wide cracks in the beams. In extreme fire environment, prestressed RPC beams that are under-reinforced at ambient temperature may fail as the low-reinforced beams. By analysing the height of the crushed zones, cracking patterns and failure modes, it was observed that PRPCB2, PRPCB3, UPRPCB1 failed as low-reinforced beams in fire.
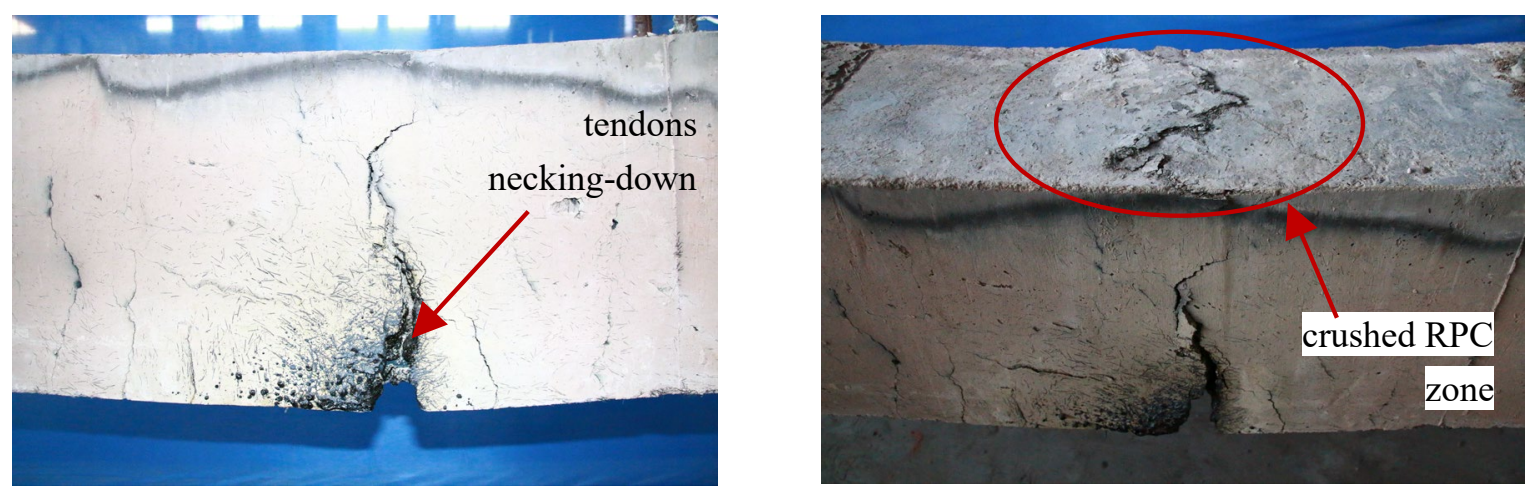

(a) tendons necking-down
(b) RPC crushed in small height of compression zone

Fig.15 Typical failure mode of tested beams(UPRPCB1)

The calculation of average crack spacing for NSC beam comprehensively considers $d_{\mathrm{eq}} / \rho_{\text {te }}$, the ratio of equivalent diameter to reinforcement ratio of longitudinal rebar, and the effect of concrete cover thickness[28]. The calculated average crack spacings are tabulated in Table 3. Note that the effect of steel fibres on cracking control did not account in this calculation. In fact, the addition of steel fibres can increase the reinforcement ratio of longitudinal rebar $\left(\rho_{\mathrm{te}}\right)$ in tension zone theoretically[29]. Additionally, the mechanical interlocking strength between aggregates and rebars is higher in the vicinity of the cracks, while the chemical adhesive strength is higher beyond the cracks. RPC does not contain coarse aggregate, the interlocking between the rugged surface of rebars and RPC is strong, and the equivalent diameter of rebar in RPC is similar to that in NSC. Therefore, the steel fibres in RPC can reduce the width and the spacing of average crack.

Table 3. Fire test results of specimens

\begin{tabular}{ccccc}
\hline specimens & $\begin{array}{c}\text { Designed average } \\
\text { crack spacing }(\mathrm{mm})\end{array}$ & $\begin{array}{c}\text { Measured average } \\
\text { crack spacing }(\mathrm{mm})\end{array}$ & $\begin{array}{c}\text { Crushed RPC } \\
\text { height }(\mathrm{mm})\end{array}$ & $\begin{array}{c}\text { Fire resistance } \\
(\mathrm{min})\end{array}$ \\
\hline PRPCB1 & 103.5 & 198.5 & - & - \\
PRPCB2 & 103.5 & 200.3 & 14.0 & 116 \\
PRPCB3 & 107.2 & 229.6 & 17.5 & 131 \\
PRPCB4 & 103.5 & 207.3 & 21.0 & 140 \\
PRPCB5 & 103.5 & 221.8 & - & - \\
PRPCB6 & 103.5 & 215.9 & 29.5 & 159 \\
UPRPCB1 & 167.8 & 238.7 & 19.0 & 127 \\
UPRPCB2 & 167.8 & 242.1 & 25.5 & 142 \\
\hline
\end{tabular}

To determine the equivalent diameter according to principle of bonding equivalent, the relative bonding characteristic coefficients of rebars and post-tensioned bonded prestressing tendons were 1.0 and $0.5[28]$. Under fire exposure, the bonding performance as well as relative bonding characteristic coefficients of reinforcement declines, and $d_{\mathrm{eq}}$ increases with the rising temperature. Moreover, the mechanical properties of reinforcement tendons degrade with the increasing temperature, resulting in a lower effective reinforcement ratio. Therefore, the average crack spacing in fire significantly increases. Compared with the calculated average crack spacing at ambient temperature (103.5-167.8mm), the measured data were relative big exposed to fire(198.5-242.1mm). 


\section{Factors affecting the fire resistance performance of prestressed RPC beams}

In order to get a better understanding of the fire behaviour of prestressed RPC beams, the effect of three significant parameters on their response was also investigated: cover thickness of tendons, load ratios, Bonded and unbonded classification of tendons.

\subsection{Cover thickness of tendons $\left(C_{\mathrm{p}}\right)$}

The all seven beams except for PRPCB3 possessed the same $P P R(0.69)$. At ambient temperature, the contributions of RPC in compression zone, tendons and rebars were $22 \%, 54 \%$ and $24 \%$ respectively. $C$ was smaller than $C_{\mathrm{p}}$, and the deterioration in strength of the RPC within $C_{\mathrm{p}}$ was much higher than that of tendons. Therefore, it can be inferred that tendons are the major contributor to the tensile strength of the specimens. Moreover, tendons are much vulnerable to elevated temperatures, mechanical properties, relaxation and creep as examples, especially for the high-level prestressed tendons in $300-600^{\circ} \mathrm{C}$. Based on the analysis above, it is reasonable that $C_{\mathrm{p}}$ can significantly affect the fire endurance. As given in Table 3 , $C_{\mathrm{p}}$ of beams PRPCB2, PRPCB4 and PRPCB6 were $35 \mathrm{~mm}, 45 \mathrm{~mm}$ and 55mm respectively, corresponding to the temperatures in tendons at 110 mins fire exposure of $576^{\circ} \mathrm{C}, 439^{\circ} \mathrm{C}$ and $313^{\circ} \mathrm{C}$. Simultaneously, the mid-span deflections of three tested beams were at the stages of failure, rapid-growth and slow-growth separately, and their fire endurance were 116 mins, 140 mins and 159 mins.

\section{2 load ratios}

The essence of fire endurance is that the fire-induced deterioration of bending capacity degrades to loading-induced bending moment. Therefore, load ratios and preload have a significant impact on the fire response of beam. At the same 100 mins of fire exposure, the deflection of PRPCB2 (with the load ratios of 0.3), was 114mm; while, that of PRPCB1(with the load ratios of 0.5 ) was only $43 \mathrm{~mm}$ at slow-growth stage. The failure time (indicated by the limited deflection) of the six beams, with high load ratios $(0.5)$, ranged from 115 mins to 160 mins. However, with the same heating time, the other two beams with the load ratios of 0.3 were even not attained their fire endurance (only $48-97 \mathrm{~mm}$ of deflection at slow-growth stage). This can be explained that the residual strength after fire exposure is greater than the loading-induced strength. Consequently, the beams with lower load ratios did not fail after fire exposure and their deflections showed obvious recovery after unloading.

\subsection{Bonded and unbonded classification of tendons}

In full length range, the temperature of tendons at the mid-span was highest. For the unbonded prestressed beams, the raised cross-sectional temperatures at the mid-span causing the obvious relaxation 
and creep under high stress condition. Because of no tangential constraint on surface of unbonded tendons in the beams, severe prestress loss transferred to the whole span of the tested beams. The loss of prestress transferring in the bonded prestressed beams was relatively smaller, resulting from the reliable bonding effect between the tendons and the surrounding RPC inhibited the transfer of prestress loss.

Compared with the bonded prestressed beams with same characteristics, the unbonded prestressed beams presented a higher deflection and attained their fire endurance within a short time (10-15 mins) when the temperatures in the prestressed tendons reached above $400^{\circ} \mathrm{C}$. This mainly resulted from the wider cracks on the bottom caused by the large deflection exposed the tendons to fire directly, exacerbating the bearing capacity degradation. From the evolution of prestress at beam ends, the bonded prestressing tendons expressed a better performance, while the prestress in unbonded prestressing tendons continuously degraded to beam failure. For the continues beams and slabs, the loss of prestress transferring of unbonded prestressing tendons could increase the risk of overall fail in partial fire condition. It can be inferred that bonded prestressed RPC beams possess a much better fire behaviour than unbonded prestressed RPC beams. Therefore, the whole scale transferring effect of prestress loss on unbonded beams should be taken into consideration when structural system design for fire resistance.

\section{Conclusion}

This study evaluated the fire exposure behaviour of eight full-scaled prestressed RPC beams utilising the combined technologies of hot-air curing and influence of steel fibre. The following conclusion were observed from the tested beams:

(1) By using the $150^{\circ} \mathrm{C}$ hot air curing, the prestressed RPC beams with a high stress level did not perform obvious spalling in ISO 834 standard fire, and all the beams maintained good integrity. $150^{\circ} \mathrm{C}$ high temperature can significantly reduce vapor pressure effect by accelerating the escape of evaporating free water, additionally, it also can improve the tensile strength of RPC to resist thermal stress effect by promoting the cement hydration and pozzolanic reaction. $150^{\circ} \mathrm{C}$ hot air curing could be an excellent way to prevent RPC fire-induced spalling, and also to boost RPC strength increase in short term.

(2) The load ratios and cover thickness of tendons are the key factors affecting the fire resistance of the prestressed RPC beams. With a load ratio 0.5 and a cover thickness of tendons $55 \mathrm{~mm}$, the beams could satisfy the fire safety requirement of $2.5 \mathrm{~h}$. Prestressed RPC beams that are under-reinforced at ambient temperature may fail as the lightly reinforced beams in fire.

(3) Compared with equivalent unbonded prestressed RPC beams, bonded prestressed RPC beams 
possess better attributes on fire resistance. Since the whole scale transferring of huge prestress loss on unbonded tendons caused by stress relaxation and creep at elevated temperatures, the process of deterioration on the beams in fire is accelerated. The whole scale transferring effect of prestress loss on unbonded beams should be considered for fire resistance performance design based on structural systems.

\section{Acknowledgements}

The work in this paper was supported by National Natural Science Foundation of China (Nos. 51878399 and 51408341). 